\title{
Crabs Go With the Flow: Declining Conductivity and Cooler Temperatures Trigger Spawning Migrations for Female Giant Mud Crabs (Scylla serrata) in Subtropical Estuaries
}

\author{
Daniel E. Hewitt ${ }^{1,2} \mathbb{D} \cdot$ Yuri Niella ${ }^{3} \mathbb{D} \cdot$ Daniel D. Johnson $^{2} \mathbb{D} \cdot$ lain M. Suthers ${ }^{1,4} \mathbb{D} \cdot$ Matthew D. Taylor $^{1,2} \mathbb{D}$
}

Received: 1 December 2021 / Revised: 11 February 2022 / Accepted: 13 February 2022 / Published online: 1 March 2022

(c) The Author(s) 2022

\begin{abstract}
Spawning is a key life history event for aquatic species that can be triggered by environmental signals. For estuarine-dependent species, the timing of such triggers can be important for determining future patterns in recruitment. Here, we used acoustic telemetry to identify the potential drivers of spawning migration in female Giant Mud Crabs (Scylla serrata). Eighty-nine mature female crabs were tagged in two subtropical south-east Australian estuaries, the Clarence River $\left(\sim 29.4^{\circ} \mathrm{S}\right)$ and Kalang River $\left(\sim 30.5^{\circ} \mathrm{S}\right)$, during the summer spawning season (November-June) over two years (2018/19 and 2020/21), and their movements were monitored for up to $68 \mathrm{~d}$, alongside high-resolution environmental data. Crabs were considered to have 'successfully' migrated if they were detected at the mouth of the estuary, a behaviour exhibited by $52 \%$ of tagged crabs. The highest probability of migration was associated with relatively low temperatures $\left(<22{ }^{\circ} \mathrm{C}\right)$ and when conductivity rapidly declined $\left(<-10 \mathrm{mS} \mathrm{cm}^{-1} \mathrm{~d}^{-1}\right)$ following heavy rainfall. Furthermore, migration coincided with larger tides associated with the new and full moon, and following heavy rainfall, which may aid rapid downstream migration. Oceanic detections of 14 crabs (30\% of 'successful' migrators) showed that once crabs left estuaries they migrated north. These patterns show that variability in environmental triggers for spawning migrations may contribute to interannual variation in spawning patterns, which may in turn impact fisheries productivity in this region.
\end{abstract}

Keywords Movement $\cdot$ Acoustic telemetry $\cdot$ Fisheries productivity $\cdot$ Crustacean $\cdot$ Integrated Marine Observing System . Recruitment variability

\section{Introduction}

Spawning is a key life history event for aquatic species, and its relationship with recruitment is often well defined (Cury et al. 2014; Kell et al. 2016). Successful recruitment is a

Communicated by Judy Grassle

Daniel E. Hewitt

daniel.hewitt@unsw.edu.au

1 Centre for Marine Science \& Innovation, School of Biological, Earth and Environmental Science, University of New South Wales, New South Wales, Sydney 2052, Australia

2 New South Wales Department of Primary Industries, Port Stephens Fisheries Institute, Locked Bag 1, 2315 Nelson Bay, Australia

3 Department of Biological Sciences, Macquarie University, Sydney, NSW, Australia

4 Sydney Institute of Marine Science, Mosman, NSW, Australia function of adequate egg production, larval growth and survival, and favourable advection to suitable nursery habitats (Cowen and Sponaugle 2009; Szuwalski et al. 2015; Kell et al. 2016). All these factors can be influenced by prevailing physicochemical conditions (e.g. Heasman and Fielder 1983; Kjesbu et al. 2010), the influence of which is in part determined by spatiotemporal patterns in spawning (e.g. Ciannelli et al. 2015; Schilling et al. 2020). Many estuarine species, such as portunid crabs, have a biphasic life cycle characterized by an oceanic larval phase and a juvenile-adult estuarine phase (Norse 1977; Elliott et al. 2007). These species often undertake broad-scale migrations towards the ocean to spawn which, in subtropical-temperate systems, may be triggered by seasonal shifts in temperature or weather events (e.g. rainfall/ 
estuarine inflow), but fine-scale processes, including lunar and diel cycles, can also play a role (Pittman and McAlpine 2003; Nemeth 2009).

The timing and intensity of environmental triggers can in turn alter the timing of spawning (e.g. Rogers and Dougherty 2019; Slesinger et al. 2021), which may have significant implications for recruitment and fisheries productivity (Schilling et al. 2020). For example, mismatches between triggers for migration and optimal conditions for egg and larval development can result in poor (or failed) recruitment (e.g. Pankhurst and Munday 2011; Asch et al. 2019). Furthermore, unfavourable advection can arise if spawning occurs at inappropriate locations, which can inhibit larval supply to estuarine nurseries (Roughan et al. 2011; Schilling et al. 2020). Therefore, quantitative estimates of triggers for spawning migrations provide a foundation to assess potential drivers of recruitment variability.

Coastal marine environments across south-eastern Australia are generally characterized by high variability, which is coupled with the climate (Scanes et al. 2020; Malan et al. 2021), and this region is considered a climate change 'hot spot' (Frusher et al. 2013; Hobday and Pecl 2014). For example, the East Australian Current (EAC), which facilitates connectivity among exploited estuarine populations in this region (Roughan et al. 2011; Everett et al. 2017; Schilling et al. 2020), is highly variable on seasonal to multi-decadal timescales (Oke et al. 2019). Further, the EAC is warming and extending poleward in response to climate change (Cetina-Heredia et al. 2014; Malan et al. 2021; Li et al. 2021), leading to ecological disruptions including reduced seabird foraging success (Carroll et al. 2016) and species redistributions (Hill et al. 2016; Niella et al. 2020b; 2021). Estuaries in this region are rapidly warming in response to climate change (Gillanders et al. 2011; Scanes et al. 2020), and rainfall events, which promote estuarine inflow, are predicted to become more sporadic and intense (Jones et al. 2009). For biphasic species in this region, environmental variability may lead to mismatches between estuarine triggers for migration and spawning and optimal conditions for larval development and dispersal in the coastal ocean.

Giant Mud Crab (Scylla serrata) is a portunid crab (Family: Portunidae) that is broadly distributed throughout the Indo-West Pacific (Keenan et al. 1998). In south-eastern Australia, the species supports high-value commercial, recreational and indigenous fisheries (West et al. 2016; Grubert et al. 2018), but catches can be highly variable (Meynecke et al. 2012). Some of this variation can be attributed to changes in catchability (Hill et al. 1982; Williams and Hill 1982), but variability in environmental conditions (e.g. rainfall, ENSO) during the early life history may also contribute to recruitment variability (Robins et al. 2005; Meynecke et al. 2012). The Giant Mud Crab is short-lived and fast-growing, with a biphasic life cycle whereby larvae disperse in ocean currents (Alberts-Hubatsch et al. 2016) before settlement in the inshore region as megalopae and subsequent recruitment to estuaries (as crablets; Webley et al. 2009), where they inhabit sub- and intertidal habitats (e.g. seagrass, mangroves, mudflats; Hill et al. 1982; Hyland et al. 1984). Females mature rapidly (after $\sim 12$ months; Heasman 1980) typically mating from mid-spring-early autumn (austral; October to March; Heasman et al. 1985). They are then thought to undertake a terminal migration to spawn in oceanic waters. This is based on the absence of ovigerous (egg-bearing) females in estuarine waters (Hill et al. 1982; Hyland et al. 1984) and incidental catches in offshore prawn trawls (Hill 1994). The triggers of this migration are unclear (Alberts-Hubatsch et al. 2016), but they are likely to be important in determining the timing and location of spawning, and thus affect later recruitment. The impact of these triggers is likely to be exacerbated in south-eastern Australia, given the aforementioned environmental variability and that this region is the southern extent of the species range (Gopurenko and Hughes 2002).

Acoustic telemetry has been broadly applied to fisheries research (Hussey et al. 2015; Taylor et al. 2017a) and is a powerful tool for quantifying environmental drivers of marine animal movement (Payne et al. 2014), at high-resolution, over broad spatial scales (Brodie et al. 2018a). Here, we sought to identify environmental conditions that triggered female Giant Mud Crab spawning migrations within south-eastern Australia. Specifically, this was achieved by 1) tracking the movement of mature females tagged with acoustic tags during the spawning season; and 2) recreating the most likely trajectories of tracked crabs between consecutive detections (Niella et al. 2020a) within study estuaries and extracting movement variables (i.e. presence/absence of migration) to model using high-resolution environmental data.

\section{Methods}

\section{Study Systems}

The Clarence River $\left(\sim 29.4^{\circ} \mathrm{S}\right.$; Fig. 1a) and Kalang River $\left(\sim 30.5^{\circ} \mathrm{S}\right.$; Fig. $\left.1 \mathrm{~b}\right)$ are located on the mid-north coast of south-eastern Australia (Fig. 1c). They both have permanently open entrances with a pronounced salinity gradient from their mouths to the upper reaches. The Clarence River is the largest estuarine system $\left(\sim 89 \mathrm{~km}^{2}\right)$ in New South Wales (Australia), while the Kalang River is comparatively small $\left(\sim 8 \mathrm{~km}^{2}\right)$ and adjoins the Bellinger River near the mouth (Fig. 1b). Both systems are mature wavedominated barrier estuaries (Roy et al. 2001; Scanes et al. 2017) that support habitats typical of riverine estuaries including saltmarsh and mangrove, and remnant seagrass beds, generally found near the mouth (Creese et al. 2009; Taylor et al. 2017b). Seasonal recreational fishing takes place in both estuaries from November-May. The entire 

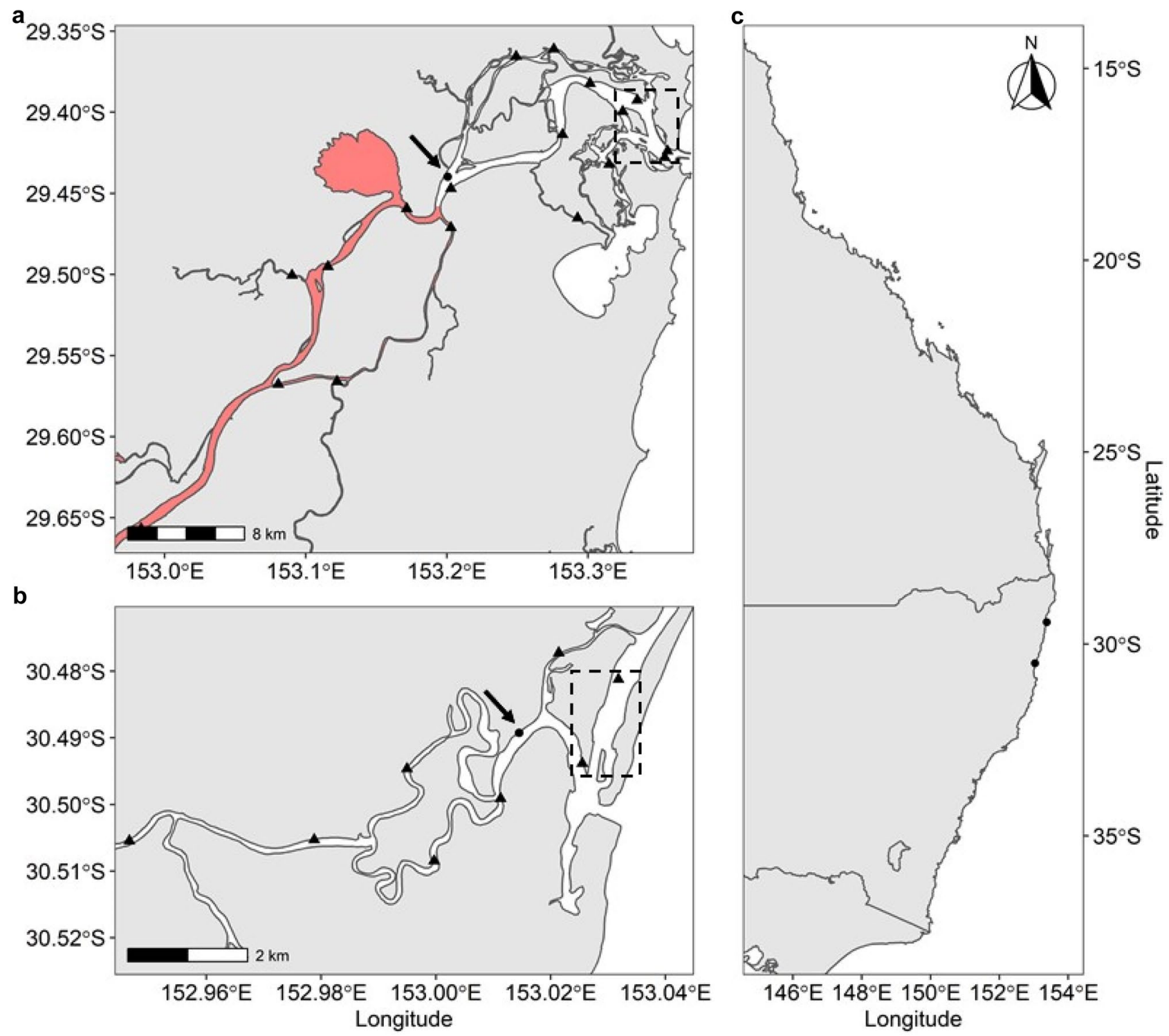

Fig. 1 Map of Clarence River (a) and Kalang River (b) showing linear array of receivers ( $\boldsymbol{\Lambda}$; receivers not used in analysis indicated by $\mathbf{O}$ ) and their location on east Australian coast (c). Dashed boxes indicate receivers considered the mouth of the estuary (i.e. indicating successful migration).

Kalang River has been closed to commercial crab fishing since 2002, and there is a partial commercial closure in the Clarence River (Fig. 1a). The commercial harvest of Giant Mud Crab in the open section of the Clarence River is significant (Meynecke et al. 2012).

\section{Crab Capture and Tagging}

Giant Mud Crabs were tagged during the austral summer-autumn (November-June) in 2018/19 and 2020/21 (Table 1). Crabs were captured using collapsible mesh traps (i.e. pots; 0.9-m diameter $\times 0.27-\mathrm{m}$ high $)$, with $55-\mathrm{mm}$ mesh and two $(0.25 \times 0.05-\mathrm{m})$
Black arrow indicates reference logger used for analysis (see 2.5 Data Analysis section). Note red shading in (a) indicates closure to crab trapping in Clarence River

semi-closed funnel entrances. Captured crabs were inspected to identify sex and all males were immediately released. Females were cooled for 10-20 s in an ice/sea-water slurry, and carapace length (CL; nearest $\mathrm{mm}$ ) and moult stage were then recorded (Hay et al. 2005). The size at maturity for Giant Mud Crabs in NSW is unknown; however, Heasman (1980) reports the size at $50 \%$ maturity for female Giant Mud Crabs in the nearby Moreton Bay ( 27.1 ${ }^{\circ} \mathrm{S}$; Queensland) as $147-\mathrm{mm}$ carapace width (CW). This corresponds to 100-mm CL on the basis of the following linear relationship:

$C L=0.68 \times C W-1.51$ 
Table 1 Tagging and detection information for female Giant Mud Crabs in Clarence River and Kalang River

\begin{tabular}{|c|c|c|c|c|c|c|c|c|c|}
\hline Estuary & Tracking period & $n$ & $\begin{array}{l}\text { Mean CL } \\
(\mathrm{mm} ; \pm \mathrm{SD})^{\mathrm{a}}\end{array}$ & $n$ detected $^{\mathrm{b}}$ & $n$ migrated $^{\mathrm{b}}$ & $\begin{array}{l}\text { Mean tracking } \\
\text { duration }(\mathrm{d} ; \pm \mathrm{SD})^{\mathrm{c}}\end{array}$ & $\begin{array}{l}\text { Mean migration } \\
\text { duration }(\mathrm{d} ; \pm \mathrm{SD})^{\mathrm{d}}\end{array}$ & $\begin{array}{l}\text { Mean } \\
\text { distance } \\
(\mathrm{km} ; \pm \mathrm{SD})\end{array}$ & $\begin{array}{l}\text { Maximum } \\
\text { speed } \\
\left(\mathrm{m} \mathrm{s}^{-1}\right)^{\mathrm{e}}\end{array}$ \\
\hline \multirow[t]{2}{*}{$\begin{array}{l}\text { Clarence } \\
\text { River }\end{array}$} & $\begin{array}{l}\text { February-May } \\
2019\end{array}$ & 42 & $109.5( \pm 6.1)$ & $30(71 \%)$ & $21(50 \%)$ & $23.6(16.9)$ & $9.6(5.6)$ & $25.9(6.6)$ & 1.9 \\
\hline & $\begin{array}{l}\text { November- } \\
\text { December } \\
2020\end{array}$ & 10 & $107.8( \pm 4.4)$ & $9(90 \%)$ & $5(50 \%)$ & $10.7(7.1)$ & $4.0(2.4)$ & $26.6(6.8)$ & 1.3 \\
\hline \multirow[t]{2}{*}{$\begin{array}{l}\text { Kalang } \\
\text { River }\end{array}$} & $\begin{array}{l}\text { February-June } \\
2019\end{array}$ & 18 & $107.5( \pm 4.9)$ & $17(94 \%)$ & $13(72 \%)$ & $12.2(16.2)$ & $6.5(8.3)$ & $4.8(1.3)$ & 0.3 \\
\hline & $\begin{array}{l}\text { January-April } \\
2020\end{array}$ & 19 & $110.6( \pm 8.0)$ & $17(89 \%)$ & $8(42 \%)$ & $12.4(11.0)$ & $6.6(8.6)$ & $6.0(2.2)$ & 0.5 \\
\hline
\end{tabular}

${ }^{\mathrm{a}} \mathrm{CL}$ : carapace length

${ }^{b}$ Values in parentheses denote percentage of all tagged crabs

${ }^{c}$ Values derived only from crabs that migrated (i.e. detected at mouth of estuary)

${ }^{\mathrm{d}}$ Time (d) between first downstream movement (i.e. onset of migration) and detection at mouth of estuary

${ }^{\text {e}}$ Since our analysis assumes constant movement between detections values represent minimum average speed

derived from morphometric data $\left(R^{2}=0.97\right)$ collected from 260 female Giant Mud Crabs in the nearby Red Rock River $\left(\sim 30.0^{\circ} \mathrm{S}\right.$; NSW; Butcher, unpublished data). Therefore, only crabs that were likely to be mature (i.e. $>100-\mathrm{mm} \mathrm{CL}$ ) and recently moulted were tagged (i.e. post- or intermoult; Hay et al. 2005), to limit the probability of tag loss during ecdysis. The capture of mature male and female crabs together suggests that these females may have recently mated and would therefore be prepared for a spawning migration. Innovasea V9-2x acoustic tags (24-mm length; 9-mm diameter; wet weight: 2-g; Innovasea, Nova Scotia, Canada; hereafter referred to as 'tags') were affixed to the posterior carapace using instant adhesive (Loctite 406, Henkel Adhesives, Australia) which has shown tag retention of at least 3 months in lab experiments (M. Taylor, unpublished data). After tagging, crabs were submerged alongside the research vessel and once normal activity (e.g. attempted swimming) had resumed crabs were released at their capture locations (generally in $2-5-\mathrm{m}$ of water). In general, negative impacts (e.g. stress, limb loss) are low for crabs handled and released in this manner (Butcher et al. 2012) and previous tagging studies have not recorded any notable impacts on normal behaviour (e.g. Hill 1978; Alberts-Hubatsch 2015).

\section{Tag Programming and Array Design}

Tags were programmed to emit a unique signal $(69 \mathrm{kHz})$, at a high-power output ( $151 \mathrm{~dB}$ re $1 \mu \mathrm{Pa}$ at $1 \mathrm{~m})$, at randomly spaced intervals of 90-150 s. Random signal transmission times were employed to minimize potential signal overlap which can block detection and to conserve battery life (estimated 346-d at these settings). Linear arrays of Innovasea VR2W acoustic receivers $(69 \mathrm{kHz})$ were deployed along all main arms, and downstream of every confluence, of the Clarence River ( $n=19$; Fig. 1a) and Kalang River $(n=9$; Fig. 1b), respectively. Receivers were fixed to existing infrastructure or independent moorings via a weighted float and anchor system. Detection ranges for the receivers in similar estuaries was estimated to be $280-420-\mathrm{m}$, with a missed detection probability of $0.4-2.7 \%$ (e.g. Walsh et al. 2012). In both estuaries, these detection ranges intersected with either the shoreline, or overlapped with the range of a neighbouring receiver in wider parts of the estuary (except for the receiver furthest from the mouth in the Clarence River; Fig. 1a), forming a series of 'gates', to minimize the chance that a crab could migrate without being detected. In addition, a series of HOBO U24-002-C conductivity/salinity loggers (hereafter referred to as 'loggers'; Onset Computer Corporation, Massachusetts, USA) were deployed in the Clarence River ( $n=5$; Fig. 1a) and Kalang River $(n=3$; Fig. 1b), which recorded temperature $\left({ }^{\circ} \mathrm{C}\right)$ and conductivity $\left(\mathrm{mS} \mathrm{cm}^{-1}\right)$ at hourly intervals.

\section{Data Collection and Storage}

Receivers were downloaded every 3-8 months using VUE software (v. 2.6.2; Innovasea, Amirix, Nova Scotia, Canada) and detections were subsequently uploaded to the Integrated Marine Observing System Animal Tracking Facility (IMOS ATF, https://animaltracking.aodn.org.au; Taylor et al. 2017a). In addition to detections from each array, the IMOS ATF and NSW DPI Shark Management Strategy acoustic array (Spaet et al. 2020a, b) were interrogated for oceanic (i.e. postestuarine) detections. Loggers were downloaded using a Universal Optic USB Base Station (and coupler) and HOBOware Pro (v. 3.7.21; Onset Computer Corporation, Massachusetts, USA). Start- and end-point calibrations were applied to conductivity data, to account for any 'data drift', by taking 
conductivity measurements at the approximate depth of the logger upon download using a Horiba U-52 MultiParameter Water Quality Meter (Instrument Choice, Synotronics Pty Ltd., South Australia). Finally, to quantify potential recaptures and encourage the release of tagged crabs, signage was posted at commonly used boat ramps in each estuary, which included project details and a dedicated recapture hotline.

\section{Data Analysis}

All statistical analyses were conducted in R (v. 4.0.2) language for statistical computing (R Development Core Team 2019), with general data wrangling carried out using the suite of functions/packages provided by 'tidyverse' (Wickham et al. 2019). Detection data were preprocessed using the 'explore' function in the R package 'actel' (Flávio and Baktoft 2021) to evaluate, and remove, potentially spurious detections (e.g. using criteria such as individuals 'skipping' receivers, implausible swimming speeds, etc.). Whenever consecutive detections implied movement speeds greater than the maximum recorded for Giant Mud Crabs (i.e. $>0.56 \mathrm{~m} \mathrm{~s}^{-1}$; AlbertsHubatsch 2015), we further inspected detections based on considerations of array design (e.g. proximity of neighbouring receivers, detection range) and river flow. Initially, this prompted several warnings of swim speeds $>>0.56 \mathrm{~m} \mathrm{~s}^{-1}$. In both estuaries the receivers recording these detections were likely to have overlapping detection ranges and to be in areas with high flow velocities (e.g. Reinfelds et al. 2004). As such, detections from one of each of these pairs of receivers were excluded from further analysis (Fig. 1a and b). Subsequent analysis indicated maximum swim speeds of up to $1.9 \mathrm{~m} \mathrm{~s}^{-1}$ in the Clarence River (Table 1). While these exceed the maximum recorded movement speed for this species (Alberts-Hubatsch 2015), these detections were retained as some uncertainty remains regarding their true maximum movement speed, particularly when riding high tidal flows in a large estuary. No individuals were flagged as skipping receivers during preprocessing.

Retained detections were used to interpolate locations of crabs using the R package 'RSP' ('Refined Shortest Paths'; Niella et al. 2020a). RSP uses a least cost path analysis to interpolate in-water locations of tagged animals between consecutive detections, at a user-specified spatial interval. This ensures that animal trajectories are realistic in systems with complex geomorphology (e.g. rivers, estuaries; Niella et al. 2020a). We interpolated continuous trajectories for crabs at $100-\mathrm{m}$ intervals. This relatively short interpolation interval was to ensure that crab trajectories adhered to the winding arms of both rivers. Since we were interested in the triggers of migration, we reduced our data to include only crabs that 'successfully' migrated to sea $(n=47)$, indicated by detection at the mouth of the estuary. In the Clarence River, we consider detection at any one of four receivers near the mouth as successful migration (Fig. 1a), due to high vessel activity and the presence of some seagrass habitats (Taylor et al. 2017b) which can decrease detection probability (Swadling et al. 2020). Similarly, we considered detections at the mouth of either the Kalang River or Bellinger River as representative of successful migration (Fig. 1b). Paths were only interpolated between estuarine detections and therefore did not include any oceanic detections.

We considered the first day where a crab exhibited overall downstream movement to be a standardized measure of the onset of migration. This was determined by comparing the daily distance to the mouth $(\mathrm{km})$ for each crab, with spatial calculations performed using the R package 'raster' (Hijmans and van Etten 2012). To model the effects of environmental variation on triggering these movements (i.e. nonmigrating/migrating) we used a generalized additive mixed model (GAMM or hierarchical GAM sensu Pedersen et al. 2019) using the R package 'mgcv' ('Mixed GAM Computation Vehicle'; Wood 2011, 2017). Within this framework, we estimated smooth functional relationships ('smooths') between the proportion of crabs beginning migration on a given day and environmental covariates, assuming a binomial error distribution (with a logit link function; Douma and Weedon 2019) via restricted maximum likelihood (REML). We modelled mean daily temperature $\left({ }^{\circ} \mathrm{C}\right)$ and conductivity ( $\mathrm{mS} \mathrm{cm}^{-1}$; which we used as a proxy for freshwater inflow/ rainfall), and the difference between these and a 3-d rolling mean (referred to as $\Delta_{-}$temperature and $\Delta_{-}$conductivity, respectively), as thin plate regression splines (Wood 2003). Patterns in both temperature and conductivity were highly similar along the length of each estuary (Supplementary Fig. 1), so values for each covariate were taken from a single reference logger passed by all crabs within each estuary (Fig. 1a and b). We also included lunar phase as a candidate variable, measured in radians ( $\mathrm{rad})$ where $0=$ new moon and $\pi=$ full moon, calculated using the R package 'lunar' (Lazaridis 2014) as a cyclic cubic spline. These splines are the sum of $k$ simpler basis functions (i.e. 'basis dimension'), where the size of $k$ determines the maximum complexity (i.e. flexibility or 'wiggliness') of the smooth. Default basis dimensions $(k=10)$ were used for all smooths and checked by computing the $k$-index for each smooth to ensure sufficient flexibility (see Wood 2017), which did not indicate any issues. Overfitting was avoided by multiplying the complexity of a smooth by an estimated smoothing penalty $(\lambda)$ and subtracting it from the model log-likelihood (Pedersen et al. 2019). We implemented variable selection within our modelling framework via the double-penalty approach (Marra and Wood 2011). This approach estimates a second penalty $\left(\lambda^{*}\right)$ that applies to flat (i.e. linear) smooths, and can allow their removal from the model if warranted (Marra and Wood 2011). To implement a mixed effects structure, we modelled year of tagging as a random effect using a factor-smooth 
Fig. 2 Example of interpolated female Giant Mud Crab tracks during spawning migration, showing daily distance to sea $(\mathrm{km})$ and path for Clarence River (a and b) and Kalang River (c and d). Refer to Fig. 1c for details regarding location on east Australian coast. See Supplementary Figs. 4-7 for all crab tracks. Note differing $x$ - and $y$-axis scales in (a) and (c) owing to different estuary lengths and tracking periods

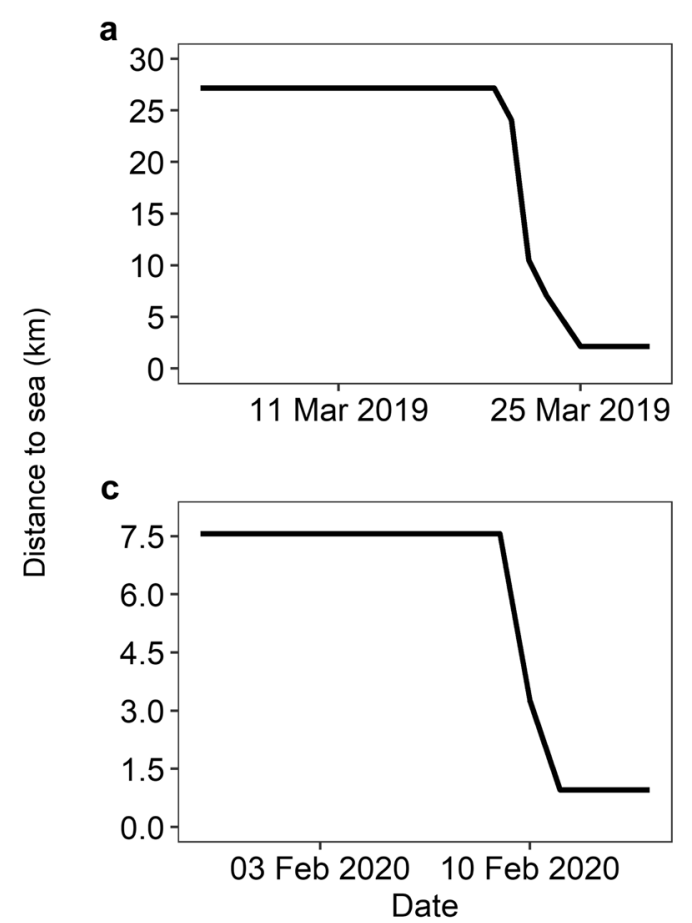

Date b

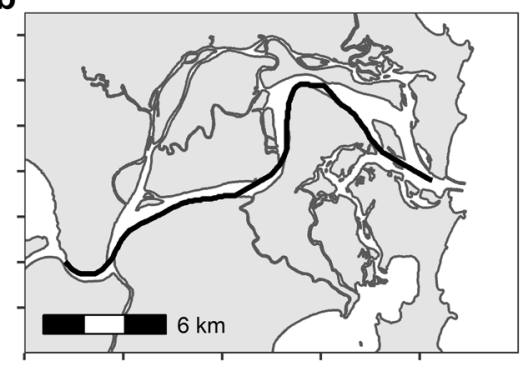

d

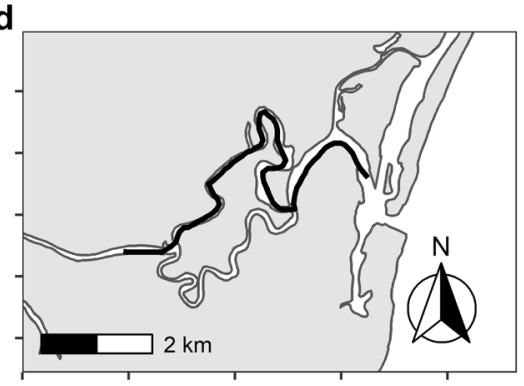

interaction (Pedersen et al. 2019). This allowed us to estimate a 'global' smooth and group-level smooths for all environmental covariates, thus permitting intergroup variation in the response (highly analogous to a GLMM with varying slopes; Pedersen et al. 2019). Model selection was conducted by applying this overall approach to two additional models that included different lengths for the rolling means of temperature and conductivity (i.e. one day and one week). All models were then compared via Akaike information criteria (AIC), where the model with lowest AIC was retained as the 'true' model (Burnham and Anderson 2002). Since these two additional models had $\triangle \mathrm{AIC} \sim 5$, and the quantitative results did not differ substantially, they were not considered further. We used 'gratia' (Simpson 2021), 'DHARMa' (Hartig 2020) and 'ggplot2' (Wickham 2016) to visually assess model assumptions (Supplementary Figs. 2 and 3), and plot back-transformed (via the inverse-logit function) probabilities of triggering the spawning migration. Finally, we described our results using the language of statistical evidence (rather than 'significance', as suggested by Muff et al. 2021) and reported the results in accordance with the suggestions in Smith (2020).

\section{Results}

In total, 89 crabs were tagged in the Clarence River $(n=52)$ and Kalang River $(n=37)$, across two austral summers (2018/19 and 2020/21) in each estuary, with mean ( \pm SD)
CL ranging from $107.4( \pm 4.9)$ to $110.6( \pm 8.0) \mathrm{mm}$ (Table 1). Of these crabs, $82 \%(n=73)$ were detected at least once, and $53 \%(n=47)$ were detected at the mouth of the estuary, indicating migration (Table 1). The remaining crabs were either not detected $(19 \% ; n=17)$ or were only detected over part of the estuary ( $29 \% ; n=26$; including two reported recaptures). Those that were detected over part of the estuary all exhibited some downstream movement (1-2-km); however, we could not determine their fate and these crabs were not included in our analysis. Across estuaries and years, temporal patterns in the spawning migration were similar. Generally, crabs exhibited a protracted resident phase ( 7-14-d), being detected on a receiver near their release location (although some were only detected during migration, likely because they resided away from a receiver), followed by a rapid migration downstream (Fig. 2; Supplementary Figs. 4-7). On average, crabs were tracked for 10.7-23.6-d; however, mean migration times (i.e. the time between their first downstream movement and detection at the mouth) were much shorter, ranging from 4.0 to 9.6 - $\mathrm{d}$ covering mean distances of $4.8-26.6-\mathrm{km}$, facilitated by maximum migration speeds of $0.3-1.9-\mathrm{m} \mathrm{s}^{-1}$ (Table 1).

Visual inspection of the interpolated tracks shows that once a crab began its migration this generally continued rapidly to the mouth of the estuary (Supplementary Figs. 5 and 7), which supports our use of the first day moving downstream as a standardized measure of the onset of migration. In both estuaries, a decline in mean daily water temperatures, following the seasonal peak, appeared to precede migration in 2019 (Fig. 3a and c), while a strong migratory response to declines in conductivity was evident in 2020 (Fig. 3b and d). These 
Fig. 3 Cumulative migration curve (solid black line) illustrating proportion of female Giant Mud Crab commencing spawning migration throughout the tracking period for each year (2018/19 and 2020/21) in Clarence River (a and $\mathbf{b}$ ) and Kalang River (c and d). Red and blue lines indicate mean daily temperature $\left({ }^{\circ} \mathrm{C}\right)$ and conductivity $\left(\mathrm{mS} \mathrm{cm}^{-1}\right)$, respectively. Vertical dashed line indicates date of tagging. Note variable scales on $x$-axis as tagging was undertaken at different times in each estuary/year
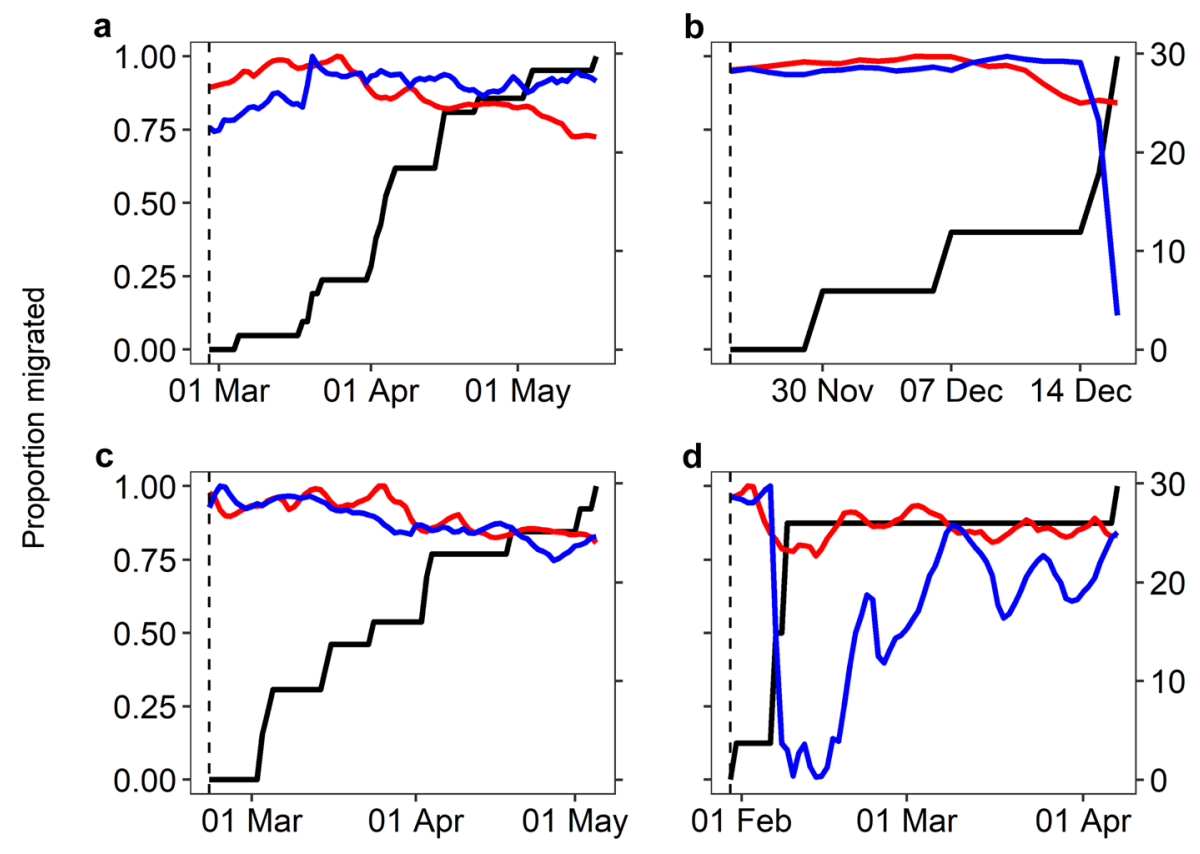

d

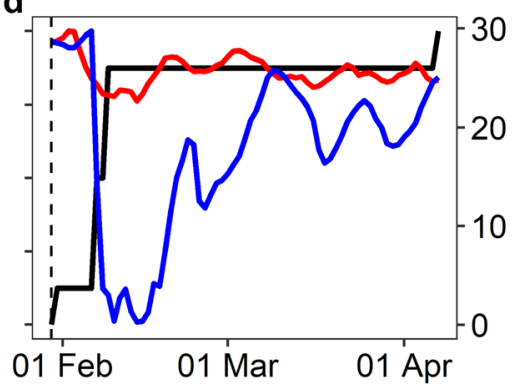

Date

observations were supported by the GAMM, which explained $47.1 \%$ of the deviance in the proportion of crabs beginning migration on a given day. Variable selection removed smooths for mean daily conductivity, $\Delta$-temperature and all grouplevel smooths (estimated degrees of freedom $<1$ ) indicating similar responses across years. We found strong evidence that cooler mean daily temperatures in the summer (i.e. $<22{ }^{\circ} \mathrm{C}$ ), resulted in the highest probability of triggering migration, which declined with increases in temperature up to $27{ }^{\circ} \mathrm{C}$ (Fig. 4a; e.d.f. $=1.78, \chi^{2}=11.38, \mathrm{P}<<0.01, n=245$ ). We also found strong evidence that intermediate to large declines in conductivity ( $\Delta$-conductivity $<-10 \mathrm{mS} \mathrm{cm}^{-1}$ ) resulted in very high migration probabilities, but with some uncertainty at the extremes of the covariate range (Fig. 4b; e.d.f. $=2.23$, $\left.\chi^{2}=19.59, \mathrm{P}<<0.01, n=245\right)$. Finally, we found strong evidence that the lunar phase had a cyclic effect on the probability of triggering the spawning migration, with the highest probabilities coinciding with the new $(\mathrm{rad}=0)$ and full moon $\left(\mathrm{rad}=\pi\right.$; Fig. $4 \mathrm{c}$; e.d.f. $\left.=5.18, \chi^{2}=26.41, \mathrm{P}<<0.01, n=245\right)$.

Oceanic detections indicated that once crabs had successfully migrated from estuaries, they continued their migration in a northern direction (Table 2; Supplementary Fig. 8). In total, $30 \%(n=14)$ of the crabs that successfully migrated (i.e. were detected at the mouth) recorded oceanic detections, and all of these were to the north of their estuary of origin at distances of 23-69-km over periods ranging from 2 to $35-\mathrm{d}$. This suggested minimum average movement speeds between 1 and 19-km d ${ }^{-1}$ once crabs were in the ocean (Table 2). No crabs were detected again within their estuary of tagging (or any other estuary) after being detected at the mouth or in the ocean.

\section{Discussion}

Our results provide evidence of environmental triggers for a downstream migration in female Giant Mud Crabs within two subtropical south-east Australian estuaries. These patterns suggest that seasonal declines in temperature, and heavy rainfall events which rapidly decrease conductivity, were responsible for triggering the observed downstream migration in mature female crabs. Additionally, high estuarine flow and large tides associated with lunar phases (i.e. new and full moons) facilitated rapid migration downstream. These findings highlight mechanistic linkages between estuarine variability and an important life history event of a highly valuable exploited species, the effects of which may influence later spawning, dispersal and recruitment processes, and ultimately impact regional fisheries productivity (Loneragan and Bunn 1999; Robins et al. 2005; Meynecke et al. 2012).

\section{Environmental Triggers of the Female Spawning Migration}

Tagged female Giant Mud Crabs exhibited a strong migratory response at low temperatures $\left(<22^{\circ} \mathrm{C}\right)$ and when conductivity 
Fig. 4 Smooth estimated probabilities of triggering female Giant Mud Crab spawning migration for mean daily temperature $\left(\mathbf{a} ;{ }^{\circ} \mathrm{C}\right), \Delta$-conductivity (b; $\mathrm{mS} \mathrm{cm}^{-1}$ ) and lunar phase (c; rad). Shaded area indicates 95\% confidence intervals and rugs along $x$-axis indicate distribution of covariate values

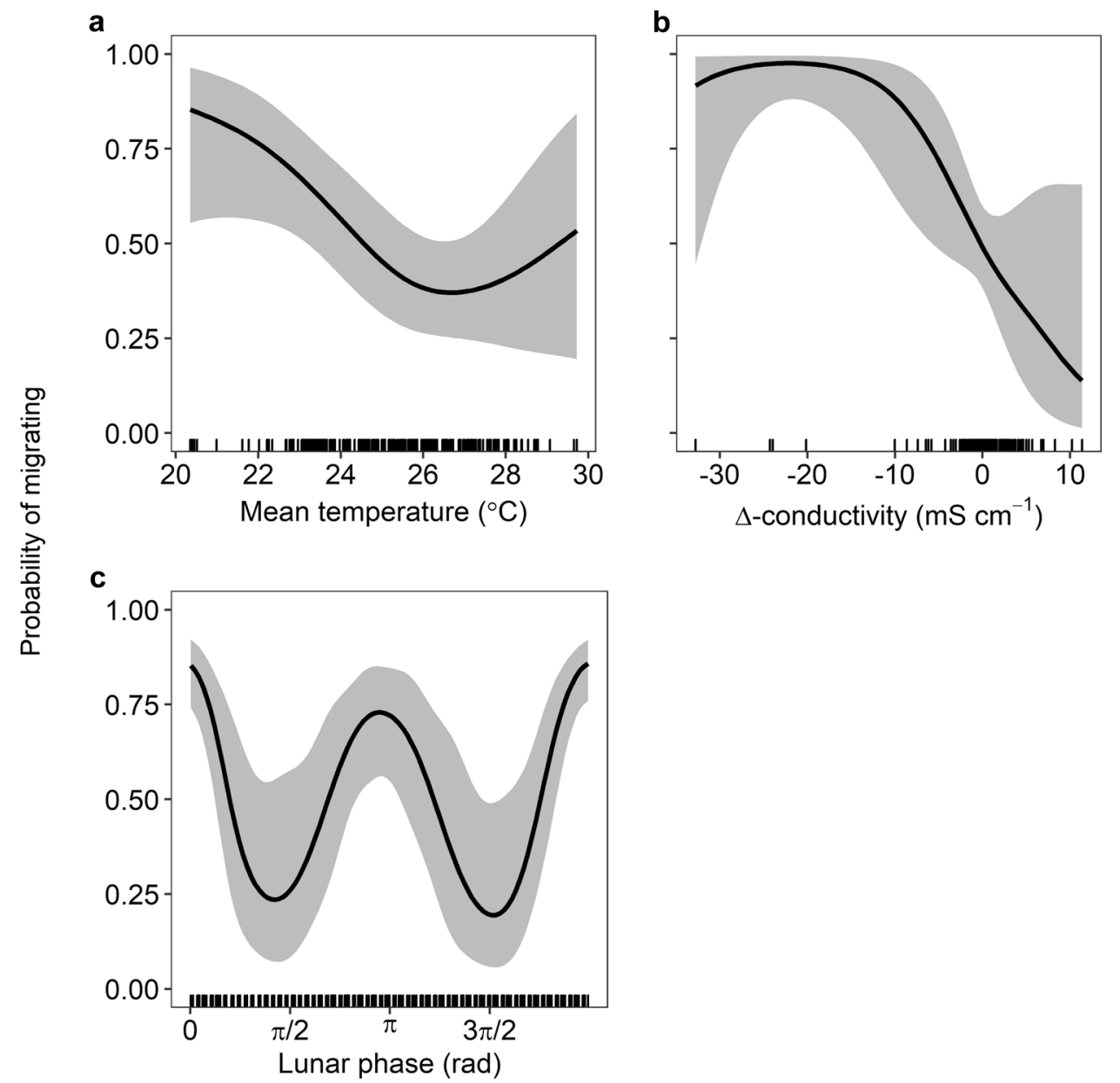

was rapidly declining. This migration enables spawning in coastal waters (Hill 1994) following seasonal peaks in mating activity during the austral spring-autumn (October-March; Heasman et al. 1985). As a predominantly estuarine species, adult Giant Mud Crabs are eurythermal (Hill 1980) and euryhaline (Davenport and Wong 1987). However, like many crab species (Anger 2001), larval growth and survival is enhanced under oceanic conditions, which include high salinities (25-30) and warm temperatures $\left(26-30{ }^{\circ} \mathrm{C}\right.$; Hamasaki 2003; Nurdiani and Zeng 2007; Baylon 2010). For Giant Mud Crab, the first larval stage does not survive at temperatures $<20{ }^{\circ} \mathrm{C}$ or $>25-30{ }^{\circ} \mathrm{C}$ (depending on region), or low salinities (<15-17.5; Hill 1974; Baylon 2010), and these conditions rarely occur inside estuaries for sustained periods. Since female Giant Mud Crabs are capable of sperm storage (Brick 1974; Raviv et al. 2008), it is likely that following mating within estuaries, the females adaptively select oceanic habitats for spawning which maximizes larval growth and survival (Ciannelli et al. 2015).

Ovigerous Giant Mud Crabs typically suppress feeding (Heasman 1980), suggesting a 'capital breeding' strategy, whereby females rely on stored energy reserves during ovarian development (Griffen 2018; Nolan et al. 2021). If this is the case, behaviours that are energetically conservative or efficient are likely to be favoured. Despite being eurythermal/ euryhaline (Hill 1980; Davenport and Wong 1987), crabs are ectotherms, and physicochemical variation can still impose an energetic cost. For example, reductions in temperature can reduce metabolism (Junk et al. 2021), while osmoregulation is required at low salinities (Chen and Chia 1996). This may explain why rates of ovarian maturation are highest at warmer (oceanic) temperatures $\left(25-26{ }^{\circ} \mathrm{C}\right.$; Heasman and Fielder 1983). In closely related species, salinities outside optima can result in smaller oocytes (e.g. Orange Mud Crab, S. olivacea; Amin-Safwan et al. 2019) or limit ovarian lipid content (e.g. Chinese Mitten Crab, Eriocheir sinensis; Long et al. 2019), which can have implications for subsequent larval development (Alava et al. 2007). Therefore, downstream migration may maximize reproductive output if females avoid suboptimal and variable metabolic conditions in estuaries during ovarian development.

Tagged female Giant Mud Crabs exhibited rapid downstream migration, covering distances of up to $40-\mathrm{km}$ in less than a week and with minimum average swimming speeds exceeding previously recorded maximum swimming speeds for the species 


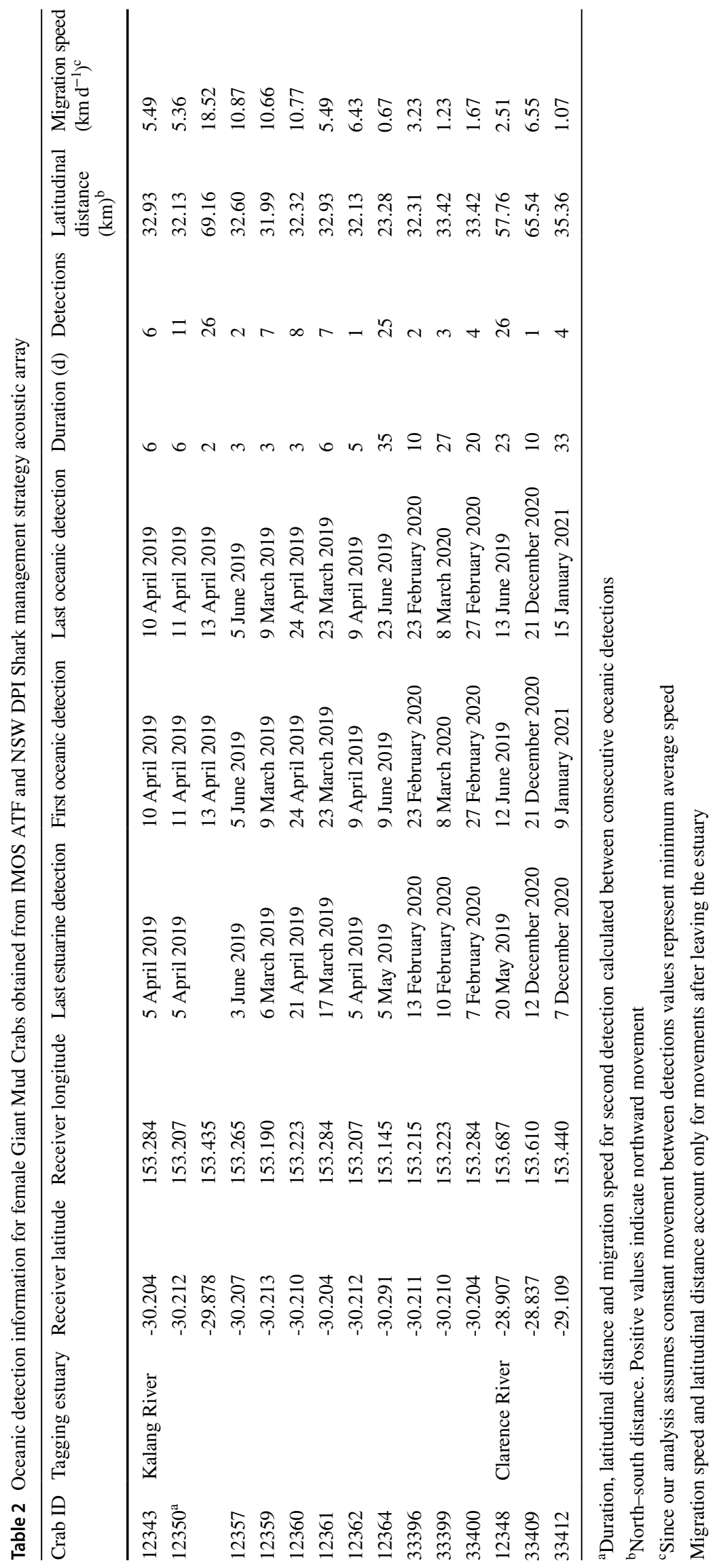


(0.56- $\mathrm{m} \mathrm{s}^{-1}$; Alberts-Hubatsch 2015). This may have been facilitated by selective tidal-stream transport (Forward and Tankersley 2001), a behaviour whereby individuals leverage periods of high flow (e.g. heavy rainfall or tidal flow) to maximize movement (Forward and Tankersley 2001). The use of selective tidal-stream transport could explain the coincidence of migration with the new and full moon — when tides are largest—and estuarine flow (e.g. following rainfall). This is a behaviour common among portunid crabs (e.g. Blue Crab, Callinectes sapidus; Carr et al. 2004) and has previously been observed in Giant Mud Crabs (Alberts-Hubatsch 2015), and may represent a strategy to minimize the energetic costs associated with migration (Forward and Tankersley 2001).

Previous oceanic recaptures of tagged female Giant Mud Crabs in south-eastern Australia suggest that once they leave estuaries they continue to migrate north; however, very few tagged crabs $(n=3)$ have been caught in the ocean in previous studies (Butcher 2005). Here we present the first evidence that this is a behaviour common across multiple years and estuaries, since all Giant Mud Crabs that were detected in oceanic waters exhibited northward movement. In south-eastern Australia, a northward spawning migration is common among estuarine-dependent species. For example, Eastern King Prawns (Penaeus [Melicertus] plebejus) and Tailor (Pomatomus saltatrix) both migrate north to spawn in oceanic waters off northern New South Wales and Queensland (Montgomery 1990; Brodie et al. 2018b; Taylor and Johnson 2021). This northward migration is probably facilitated by transient, sub-mesoscale currents that flow northward in this region (Schaeffer et al. 2017; Kerry et al. 2020); however, the mechanisms facilitating these oceanic movements should not be overinterpreted given the relatively low number of detections and a paucity of complementary environmental data at the scale necessary to confidently infer mechanisms supporting movement. Despite some studies reporting the occurrence of female Giant Mud Crabs with spent ovaries in estuaries (e.g. Heasman et al. 1985), we did not detect females within estuaries once they had migrated to sea. This offers some evidence that this is a terminal migration, but these data are insufficient to determine the reproductive mode of the species (i.e. itero- or semelparous), since Giant Mud Crabs are capable of multiple spawning after a single mating event (Brick 1974).

\section{Potential Influence of Migration on Future Recruitment and Fisheries Catch}

Oceanic spawning can facilitate connectivity among spatially distinct populations (Cowen and Sponaugle 2009) and lead to metapopulations with source-sink structures that are robust to stochastic environmental variation (Kritzer and Sale 2004). Peaks in mating activity (Heasman et al. 1985), and our data, show that conditions that trigger the female
Giant Mud Crab spawning migration typically coincide with the period of highest sea surface temperature and southward transport in the EAC (Oke et al. 2019; Kerry and Roughan 2020), which is likely to contribute to the broad genetic connectivity among estuarine populations in the region (Gopurenko and Hughes 2002). Furthermore, the northward migration of female Giant Mud Crabs coupled with the predominant southward flow of the EAC (Oke et al. 2019) suggests that a north-to-south source-sink population structure is a possibility. This means that within a given estuary, new recruits may well have originated from the north, and variation in abundance may thus be influenced by spawning stock biomass and environmental conditions outside of the estuary where juvenile crabs settle.

Recruitment variability potentially contributes to fluctuations in Giant Mud Crab abundance (Robins et al. 2005; Meynecke et al. 2012). In estuaries south of the Clarence River $\left(\sim 29.4^{\circ} \mathrm{S}\right), 20-70 \%$ of the variation in seasonally averaged catch-per-unit-effort corresponds with high austral spring (September-November) or summer (December-February) rainfall within the same estuary/catchment two years earlier, but these relationships break down when annual data are considered (Meynecke et al. 2012). Lagged relationships such as these generally suggest some influence of the physicochemical environment on spawning or early life history processes, but if new recruits are also sourced from other estuaries to the north such relationships may be less clear. Our analyses suggest that there may be a substantial influence of temperature and rainfall on the commencement of spawning activity for female crabs, but if oceanic spawning is followed by southward dispersal of larvae in the EAC then the strength of spawning signals in estuaries to the north of a given estuary may be more important for later recruitment. Further study of larval dispersal is required to identify likely source estuaries, which can be achieved via biophysical particle tracking simulations (e.g. Everett et al. 2017; Schilling et al. 2020), thereby linking factors that influence spawning processes to spatially segregated fisheries productivity.

\section{Technical Considerations and Caveats}

A central challenge when applying acoustic telemetry to any species is tag loss (Brownscombe et al. 2019; Sequeira et al. 2019). This is exacerbated when tagging crustaceans, as anything attached to the exoskeleton is shed during ecdysis (Florko et al. 2021). We endeavoured to control for this by only tagging large, recently moulted females (see 2.2 Crab Capture and Tagging), and this approach was largely successful. Ultimately, the number of crabs that migrated was within the range appropriate for determining behaviours at the population scale (Sequeira et al. 2019). While most tagged crabs migrated, some movements comprised only partial migrations (i.e. did not leave 
the estuary), which may be due to the crabs not having yet mated. It also raises the question as to whether these individuals may have had an alternate strategy of spawning within the estuary. This is highly unlikely since the capture of ovigerous Giant Mud Crabs in estuaries is extremely rare despite extensive trapping, trawling and hauling effort within such systems (Hill et al. 1982; Hyland et al. 1984; Hill 1994). It is possible that some females overwintered within the estuary before migrating and spawning in the subsequent season (Heasman et al. 1985). While the estimated battery life of our tags (346-d) was at the limit of observing this, we did not record any detections of individuals in the year following their tagging, which may suggest a degree of mortality or tag loss.

Our interpolation of crab locations assumed constant movement between detections, but this is unlikely since Giant Mud Crabs typically exhibit episodic downstream movement (Alberts-Hubatsch 2015) which may have impacted the accuracy of movement rates derived from the analysis. We overcame this limitation by modelling the onset of migration, rather than basing any inference directly on movement rate data. Detection efficiency in acoustic arrays can be impacted by several factors. These include ambient noise produced by wind or rain, biological noise (Stocks et al. 2014; Huveneers et al. 2016) and attenuation of acoustic 'pings' from animals buried (Grothues et al. 2012) or sheltered in complex habitats (e.g. seagrass; Swadling et al. 2020). In the present study, the impact of these factors appeared limited as our data preprocessing and quality control did not indicate any irregular movement patterns, such as individuals skipping receivers. Finally, one individual displayed exceptionally high migration speed in the ocean (ID: 12350; Table 2); it is also possible that this crab may have been consumed by a predator during migration (e.g. Romine et al. 2014; Wargo Rub and Sandford 2020), given that the speed observed was almost double that of any other individual.

\section{Future Research and Conclusions}

This study provides some mechanistic insight into how seasonal changes in temperature or climatic events (e.g. rainfall) may influence the spawning migration in Giant Mud Crabs. These relationships may have implications for larval supply, recruitment and fisheries productivity (Meynecke et al. 2012). While we studied movements in the southern part of the subtropical range, these patterns may reflect drivers in regions further to the north, where the species supports highvalue fisheries (although circulation and dispersal patterns may differ). Furthermore, we provide the first evidence of a northward oceanic migration in Giant Mud Crabs across multiple years and estuaries, which has previously been reported for a few individuals (Butcher 2005), and is similar to other species in the region (Ruello 1975; Brodie et al. 2018b). In conjunction with the dominating poleward flow of the EAC, these observations point to a potential northto-south source-sink model for populations in this region; however, settlement surveys (e.g. de Lestang et al. 2014) and larval dispersal simulations (e.g. Everett et al. 2017; Schilling et al. 2020) are required to fully quantify these dynamics. When coupled with other data, these findings provide a foundation for the modelling of future seasonal and interannual variation in exploited stocks, based on present-day environmental variation. Quantifying these relationships is important for guiding management decisions, such as determining total allowable catch or estuarine stocking (Taylor et al. 2017c). Such estimates are particularly important in the context of climate change, which is altering the physicochemical regimes in coastal marine environments (Frusher et al. 2013; Hobday and Pecl 2014; Scanes et al. 2020).

Supplementary Information The online version contains supplementary material available at https://doi.org/10.1007/s12237-022-01061-1.

Acknowledgements The authors would like to acknowledge B. Leach, P. Butcher, C. Brand, G. Butler, J. St. Vincent Welch, L. Stoot, T. Billin and F. Jaine for assistance with fieldwork, tagging and data collection. This project was supported by the Fisheries Research and Development Corporation (FRDC) on behalf of the Australian Government through a grant to MDT, DDJ and IMS (2017/006) and co-funded by the NSW Recreational Fishing Saltwater Trust. DEH was supported by an Australian Government Research Training Program and a NSW DPI top-up scholarship. Data were sourced from the Acoustic Animal Tracking Database (https://animaltracking.aodn.org.au) of the Integrated Marine Observing System (IMOS; www.imos.org.au), a national collaborative research infrastructure supported by the Australian Government. The database is a centralized acoustic telemetry data repository maintained by the IMOS Animal Tracking Facility (IMOS ATF) and the Australian Ocean Data Network (AODN, https://portal.aodn.org.au/). Funding bodies had no role in the design, data collection, analysis or interpretation of data. This is contribution \#286 of the Sydney Institute of Marine Science.

Author Contributions MDT, DDJ and IMS conceived the study and obtained funding. DEH, MDT, DDJ and IMS planned the acoustic arrays and fieldwork. DEH carried out the fieldwork. DEH carried out the analysis with the assistance of YN. DEH wrote the manuscript. DEH, YN, DDJ, IMS and MDT contributed critically to the drafts and gave final approval for publication.

Funding Open Access funding enabled and organized by CAUL and its Member Institutions.

Data Availability The datasets used in this study are stored on the IMOS ATF (https://animaltracking.aodn.org.au), under the NSW DPI Coastal and Estuarine Fish Tracking (CEFT) project. Additionally, the code used in our analysis can be accessed via GitHub (https://github. com/DEHewitt/gmc_spawning_migration). 


\section{Declarations}

Ethical Approval Sample collection was conducted under a Sect. 37 Scientific Collection Permit (permit P01/0059) and Animal Research Authority 13-08 issued by NSW Department of Primary Industries.

Conflict of Interest The authors declare no conflicts of interest.

Open Access This article is licensed under a Creative Commons Attribution 4.0 International License, which permits use, sharing, adaptation, distribution and reproduction in any medium or format, as long as you give appropriate credit to the original author(s) and the source, provide a link to the Creative Commons licence, and indicate if changes were made. The images or other third party material in this article are included in the article's Creative Commons licence, unless indicated otherwise in a credit line to the material. If material is not included in the article's Creative Commons licence and your intended use is not permitted by statutory regulation or exceeds the permitted use, you will need to obtain permission directly from the copyright holder. To view a copy of this licence, visit http://creativecommons.org/licenses/by/4.0/.

\section{References}

Alava, V.R., E.T. Quinitio, J.B. de Pedro, F.M.P. Priolo, Z.G.A. Orozco, and M. Wille. 2007. Lipids and fatty acids in wild and pondreared mud crab Scylla serrata (Forskål) during ovarian maturation and spawning. Aquaculture Research 38: 1468-1477. https:// doi.org/10.1111/j.1365-2109.2007.01793.x.

Alberts-Hubatsch, H. 2015. Movement patterns and habitat use of the exploited swimming crab Scylla serrata (Forskål, 1775). PhD thesis, University Bremen, Germany.

Alberts-Hubatsch, H., S.Y. Lee, J.O. Meynecke, K. Diele, I. Nordhaus, and M. Wolff. 2016. Life-history, movement, and habitat use of Scylla serrata (Decapoda, Portunidae): current knowledge and future challenges. Hydrobiologia, 763, 5-21. https://doi.org/10. 1007/s10750-015-2393-z

Amin-Safwan, A., H. Muhd-Farouk, M.P. Mardhiyyah, M. Nadirah, and M. Ikhwanuddin. 2019. Does water salinity affect the level of $17 \beta$-estradiol and ovarian physiology of orange mud crab, Scylla olivacea (Herbst, 1796) in captivity? Journal of King Saud University - Science 31: 827-835. https://doi.org/10.1016/j.jksus. 2018.08.006.

Anger, K. 2001. The biology of decapod crustacean larvae. Lisse: AA Balkema Publishers.

Asch, R.G., C.A. Stock, and J.L. Sarmiento. 2019. Climate change impacts on mismatches between phytoplankton blooms and fish spawning phenology. Global Change Biology 25: 2544-2559. https://doi.org/10.1111/gcb.14650.

Baylon, J.C. 2010. Effects of salinity and temperature on survival and development of larvae and juveniles of the mud crab, Scylla serrata (Crustacea: Decapoda: Portunidae). Journal of the World Aquaculture Society 41: 858-873. https://doi.org/10.1111/j.17497345.2010.00429.x.

Brick, R.W. 1974. Effects of water quality, antibiotics, phytoplankton and food on survival and development of larvae of Scylla serrata (Crustacea: Portunidae). Aquaculture 3: 231-244. https://doi.org/ 10.1016/0044-8486(74)90074-X.

Brodie, S., E.J.I. Lédée, M.R. Heupel, R.C. Babcock, H.A. Campbell, D.C. Gledhill, X. Hoenner, C. Huveneers, F.R.A. Jaine, C.A. Simpfendorfer, M.D. Taylor, V. Udyawer, and R.G. Harcourt. 2018a. Continental-scale animal tracking reveals functional movement classes across marine taxa. Scientific Reports 8: 3717. https://doi.org/10.1038/s41598-018-21988-5.

Brodie, S., L. Litherland, J. Stewart, H.T. Schilling, J.G. Pepperell, and I.M. Suthers. 2018b. Citizen science records describe the distribution and migratory behaviour of a piscivorous predator, Pomatomus saltatrix. ICES Journal of Marine Science 75: 1573-1582. https://doi.org/10.1093/icesjms/fsy057.

Brownscombe, J.W., E.J.I. Lédée, G.D. Raby, D.P. Struthers, L.F.G. Gutowsky, V.M. Nguyen, N. Young, M.J.W. Stokesbury, C.M. Holbrook, T.O. Brenden, C.S. Vandergoot, K.J. Murchie, K. Whoriskey, J. MillsFlemming, S.T. Kessel, C.C. Krueger, and S.J. Cooke. 2019. Conducting and interpreting fish telemetry studies: Considerations for researchers and resource managers. Reviews in Fish Biology and Fisheries 29: 369-400. https://doi. org/10.1007/s11160-019-09560-4.

Burnham, K.P., and D.R. Anderson. 2002. Model selection and multimodel inference: A practical information-theoretic approach. New York: Springer-Verlag.

Butcher, P.A. 2005. Mud crab (Scylla serrata) and marine park management in estuaries of the Solitary Islands Marine Park, New South Wales. PhD Thesis, University of New England.

Butcher, P.A., J.C. Leland, M.K. Broadhurst, B.D. Paterson, and D.G. Mayer. 2012. Giant mud crab (Scylla serrata): Relative efficiencies of common baited traps and impacts on discards. ICES Journal of Marine Science 69: 1511-1522. https://doi.org/10.1093/ icesjms/fss 109

Carr, S.D., R.A. Tankersley, J.L. Hench, R.B Forward Jr, and R.A. Luettich Jr. 2004. Movement patterns and trajectories of ovigerous blue crabs Callinectes sapidus during the spawning migration. Estuarine, Coastal and Shelf Science 60: 567-579. https:// doi.org/10.1016/j.ecss.2004.02.012.

Carroll, G., J.D. Everett, R. Harcourt, D. Slip, and I. Jonsen. 2016. High sea surface temperatures driven by a strengthening current reduce foraging success by penguins. Scientific Reports 6: 22236 . https://doi.org/10.1038/srep22236.

Cetina-Heredia, P., M. Roughan, E. van Sebille, and M.A. Coleman. 2014. Long-term trends in the East Australian Current separation latitude and eddy driven transport. Journal of Geophysical Research: Oceans 119: 4351-4366. https://doi.org/10.1002/ 2014jc010071.

Chen, J.-C., and P.-G. Chia. 1996. Oxygen uptake and nitrogen excretion of juvenile Scylla serrata at different temperature and salinity levels. Journal of Crustacean Biology 16: 437-442. https:// doi.org/10.2307/1548732.

Ciannelli, L., K. Bailey, and E.M. Olsen. 2015. Evolutionary and ecological constraints of fish spawning habitats. ICES Journal of Marine Science 72: 285-296. https://doi.org/10.1093/icesjms/fsu145.

Cowen, R.K., and S. Sponaugle. 2009. Larval dispersal and marine population connectivity. Annual Review of Marine Science 1: 443-466. https://doi.org/10.1146/annurev.marine.010908. 163757.

Creese, R.G., T.M. Glasby, and C. Gallen. 2009. Mapping the habitats of NSW estuaries. Fisheries Final Report Series 113. Port Stephens, NSW, Australia: Industry \& Investment NSW.

Cury, P.M., J.-M. Fromentin, S. Figuet, and S. Bonhommeau. 2014. Resolving Hjort's dilemma: How is recruitment related to spawning stock biomass in marine fish? Oceanography 27: 42-47. https://doi.org/10.5670/oceanog.2014.85.

Davenport, J., and T. Wong. 1987. Responses of adult mud crabs (Scylla serrata) (Forskål) to salinity and low oxygen tension. Comparative Biochemistry and Physiology Part a: Physiology 86: 43-47. https://doi.org/10.1016/0300-9629(87)90274-X.

de Lestang, S., N. Caputi, M. Feng, A. Denham, J. Penn, D. Slawinski, A. Pearce, and J. How. 2014. What caused seven consecutive years of low puerulus settlement in the western rock lobster 
fishery of Western Australia? ICES Journal of Marine Science 72: 49-58. https://doi.org/10.1093/icesjms/fsu177.

Douma, J.C., and J.T. Weedon. 2019. Analysing continuous proportions in ecology and evolution: A practical introduction to beta and Dirichlet regression. Methods in Ecology and Evolution 10: 1412-1430. https://doi.org/10.1111/2041-210X.13234.

Elliott, M., A.K. Whitfield, I.C. Potter, S.J.M. Blaber, D.P. Cyrus, F.G. Nordlie, and T.D. Harrison. 2007. The guild approach to categorizing estuarine fish assemblages: A global review. Fish and Fisheries 8: 241-268. https://doi.org/10.1111/j.1467-2679. 2007.00253.x.

Everett, J.D., E. van Sebille, M.D. Taylor, I.M. Suthers, C. Setio, P. Cetina-Heredia, and J.A. Smith. 2017. Dispersal of Eastern King Prawn larvae in a western boundary current: New insights from particle tracking. Fisheries Oceanography 26: 513-525. https:// doi.org/10.1111/fog.12213.

Flávio, H., and H. Baktoft. 2021. actel: Standardised analysis of acoustic telemetry data from animals moving through receiver arrays. Methods in Ecology and Evolution 12: 196-203. https://doi.org/ 10.1111/2041-210X.13503.

Florko, K.R.N., E.R. Davidson, K.J. Lees, L.J. Hammer, M.F. Lavoie, R.J. Lennox, É. Simard, P. Archambault, M. Auger-Méthé, C.W. McKindsey, F.G. Whoriskey, and N.B. Furey. 2021. Tracking movements of decapod crustaceans: A review of a half-century of telemetry-based studies. Marine Ecology Progress Series 679: 219-239. https://doi.org/10.3354/meps13904.

Forward, R., and R. Tankersley. 2001. Selective tidal-stream transport of marine animals. Oceanography and Marine Biology 39: 305-353.

Frusher, S., S. Jennings, M. Haward, N. Holbrook, G. Pecl, A. Hobday, C. Creighton, D. D'Silva, M. Nursey-Bray, and I. van Putten. 2013. The short history of research in a marine climate change hotspot: From anecdote to adaptation in south-east Australia. Reviews in Fish Biology and Fisheries 24: 593-611. https://doi. org/10.1007/s11160-013-9325-7.

Gillanders, B.M., T.S. Elsdon, I.A. Halliday, G.P. Jenkins, J.B. Robins, and F.J. Valesini. 2011. Potential effects of climate change on Australian estuaries and fish utilising estuaries: A review. Marine and Freshwater Research 62: 1115-1131. https://doi.org/10.1071/ Mf11047.

Gopurenko, D., and J.M. Hughes. 2002. Regional patterns of genetic structure among Australian populations of the mud crab, Scylla serrata (Crustacea: Decapoda): Evidence from mitochondrial DNA. Marine and Freshwater Research 53: 849-857. https:// doi.org/10.1071/Mf01225.

Griffen, B.D. 2018 The timing of energy allocation to reproduction in an important group of marine consumers PLoS ONE $13 \mathrm{https} / / /$ doi.org/10.1371/journal.pone.0199043

Grothues, T.M., K.W. Able, and J.H. Pravatiner. 2012. Winter flounder (Pseudopleuronectes americanus Walbaum) burial in estuaries: Acoustic telemetry triumph and tribulation. Journal of Experimental Marine Biology and Ecology 438: 125-136. https://doi. org/10.1016/j.jembe.2012.09.006.

Grubert, M., D. Johnson, D. Johnston, and S. Helmke. 2018. Giant Mud Crab (Scylla serrata). Status of Key Australian Fish Stocks. Canberra: Fisheries Research and Development Corporation.

Hamasaki, K. 2003. Effects of temperature on the egg incubation period, survival and developmental period of larvae of the mud crab Scylla serrata (Forskål) (Brachyura: Portunidae) reared in the laboratory. Aquaculture 219: 561-572. https://doi.org/10. 1016/S0044-8486(02)00662-2.

Hartig, F. 2020. DHARMa: Residual diagnostics for hierarchical (multilevel/mixed) regression models. R Package version 0.3.3.0 ed.

Hay, T., N. Gribble, C. De Vries, K. Danaher, M. Dunning, M. Hearnden, and P. Caley. 2005. Methods for monitoring the abundance and habitat of the northern Australian mud crab Scylla serrata. Fishery Report 80. Northern Territory Department of Business, Industry and Resource Development, Darwin.

Heasman, M., and D. Fielder. 1983. Laboratory spawning and mass rearing of the mangrove crab, Scylla serrata (Forskål), from first zoea to first crab stage. Aquaculture 34: 303-316.

Heasman, M., D. Fielder, and R. Shepherd. 1985. Mating and spawning in the mudcrab, Scylla serrata (Forskål) (Decapoda: Portunidae), in Moreton Bay, Queensland. Marine and Freshwater Research 36: 773-783. https://doi.org/10.1071/ MF9850773.

Heasman, M.P. 1980. Aspects of the general biology and fishery of the Mud Crab Scylla serrata (Forskål), in Moreton Bay, Queensland. PhD thesis, University of Queensland, Brisbane.

Hijmans, R.J. and J. Van Etten. 2012. raster: Geographic analysis and modelling with raster data. $\mathrm{R}$ package version $2.0 .12 \mathrm{ed}$.

Hill, B. 1974. Salinity and temperature tolerance of zoeae of the portunid crab Scylla serrata. Marine Biology 25: 21-24. https:// doi.org/10.1007/BF00395104.

Hill, B. 1978. Activity, track and speed of movement of the crab Scylla serrata in an estuary. Marine Biology 47: 135-141. https://doi. org/10.1007/BF00395634.

Hill, B. 1980. Effects of temperature on feeding and activity in the crab Scylla serrata. Marine Biology 59: 189-192. https://doi. org/10.1007/Bf00396867.

Hill, B. 1994. Offshore spawning by the portunid crab Scylla serrata (Crustacea: Decapoda). Marine Biology 120: 379-384. https:// doi.org/10.1007/Bf00680211.

Hill, B., M. Williams, and P. Dutton. 1982. Distribution of juvenile, subadult and adult Scylla serrata (Crustacea: Portunidae) on tidal flats in Australia. Marine Biology 69: 117-120. https:// doi.org/10.1007/BF00396967.

Hill, N.J., A.J. Tobin, A.E. Reside, J.G. Pepperell, and T.C.L. Bridge. 2016. Dynamic habitat suitability modelling reveals rapid poleward distribution shift in a mobile apex predator. Global Change Biology 22: 1086-1096. https://doi.org/10.1111/gcb. 13129.

Hobday, A.J., and G.T. Pecl. 2014. Identification of global marine hotspots: Sentinels for change and vanguards for adaptation action. Reviews in Fish Biology and Fisheries 24: 415-425. https://doi. org/10.1007/s11160-013-9326-6.

Hussey, N.E., S.T. Kessel, K. Aarestrup, S.J. Cooke, P.D. Cowley, A.T. Fisk, R.G. Harcourt, K.N. Holland, S.J. Iverson, and J.F. Kocik. 2015. Aquatic animal telemetry: A panoramic window into the underwater world. Science 348: 1255642. https://doi.org/10. 1126/science. 1255642.

Huveneers, C., C.A. Simpfendorfer, S. Kim, J.M. Semmens, A.J. Hobday, H. Pederson, T. Stieglitz, R. Vallee, D. Webber, and M.R. Heupel. 2016. The influence of environmental parameters on the performance and detection range of acoustic receivers. Methods in Ecology and Evolution 7: 825-835. https://doi.org/10.1111/2041-210x. 12520.

Hyland, S., B. Hill, and C. Lee. 1984. Movement within and between different habitats by the portunid crab Scylla serrata. Marine Biology 80: 57-61. https://doi.org/10.1007/Bf00393128.

Jones,D.A., W. Wang, and R. Fawcett, 2009. High-quality spatial climate data-sets for Australia. Australian Meteorological and Oceanographic Journal, 58, 233. https://doi.org/10.22499/2. 5804.003

Junk, E.J., J.A. Smith, I.M. Suthers, and M.D. Taylor. 2021. Bioenergetics of blue swimmer crab (Portunus armatus) to inform estimation of release density for stock enhancement. Marine and Freshwater Research 72: 1375-1386. https://doi.org/10.1071/ MF20363. 
Keenan, C., P.J. Davie, and D. Mann. 1998. A revision of the genus Scylla de Haan, 1833 (Crustacea: Decapoda: Brachyura: Portunidae). The Raffles Bulletin of Zoology 46: 217-245.

Kell, L.T., R.D.M. Nash, M. Dickey-Collas, I. Mosqueira, and C. Szuwalski. 2016. Is spawning stock biomass a robust proxy for reproductive potential? Fish and Fisheries 17: 596-616. https:// doi.org/10.1111/faf.12131.

Kerry,C. and Roughan, M. 2020. Downstream evolution of the East Australian Current system: Mean flow, seasonal and intraannual variability. Journal of Geophysical Research: Oceans, 125, e2019JC015227. https://doi.org/10.1029/2019JC015227

Kerry, C., M. Roughan, and B. Powell. 2020. Predicting the submesoscale circulation inshore of the East Australian Current. Journal of Marine Systems 204: 103286. https://doi.org/10. 1016/j.jmarsys.2019.103286.

Kjesbu, O.S., D. Righton, M. Krüger-Johnsen, A. Thorsen, K. Michalsen, M. Fonn, and P.R. Witthames. 2010. Thermal dynamics of ovarian maturation in Atlantic cod (Gadus morhua). Canadian Journal of Fisheries and Aquatic Sciences 67: 605-625. https://doi.org/10. 1139/F10-011.

Kritzer, J.P., and P.F. Sale. 2004. Metapopulation ecology in the sea: From Levins' model to marine ecology and fisheries science. Fish and Fisheries 5: 131-140. https://doi.org/10.1111/j.14672979.2004.00131.x.

Lazaridis, E. 2014. lunar: Lunar phase \& distance, seasons and other environmental factors. R package version $0.1-04$ ed.

Li, J., M. Roughan, and C. Kerry. 2021. Dynamics of interannual eddy kinetic energy modulations in a Western Boundary Current. Geophysical Research Letters, 48, e2021GL094115. https://doi.org/ 10.1029/2021GL094115

Loneragan, N.R., and S.E. Bunn. 1999. River flows and estuarine ecosystems: Implications for coastal fisheries from a review and a case study of the Logan River, southeast Queensland. Australian Journal of Ecology 24: 431-440. https://doi.org/10.1046/j.14429993.1999.00975.x.

Long, X., X. Wu, S. Zhu, H. Ye, Y. Cheng, and C. Zeng. 2019. Salinity can change the lipid composition of adult Chinese mitten crab after long-term salinity adaptation. PLoS ONE 14: e0219260. https://doi.org/10.1371/journal.pone.0219260.

Malan, N., M. Roughan, and C. Kerry. 2021. The rate of coastal temperature rise adjacent to a warming western boundary current is nonuniform with latitude. Geophysical Research Letters, 48, e2020GL090751. https://doi.org/10.1029/2020GL090751

Marra, G., and S.N. Wood. 2011. Practical variable selection for generalized additive models. Computational Statistics \& Data Analysis 55: 2372-2387. https://doi.org/10.1016/j.csda.2011.02.004.

Meynecke, J., M. Grubert, and J. Gillson. 2012. Giant mud crab (Scylla serrata) catches and climate drivers in Australia-a large scale comparison. Marine and Freshwater Research 63: 84-94. https:// doi.org/10.1071/Mf11149.

Montgomery, S.S. 1990. Movements of juvenile Eastern King Prawns, Penaeus plebejus, and identification of stock along the east-coast of Australia. Fisheries Research 9: 189-208. https://doi.org/10. 1016/S0165-7836(05)80001-3.

Muff, S., E.B. Nilsen, R.B. O'Hara, and C.R. Nater. 2021. Rewriting results sections in the language of evidence. Trends in Ecology \& Evolution. https://doi.org/10.1016/j.tree.2021.10.009.

Nemeth, R.S. 2009. Dynamics of reef fish and decapod crustacean spawning aggregations: underlying mechanisms, habitat linkages, and trophic interactions. In: NAGELKERKEN, I. (ed.) Ecological Connectivity among Tropical Coastal Ecosystems. Dordrecht: Springer Netherlands.

Niella, Y., Butcher, P., Holmes, B., Barnett, A. and Harcourt, R. 2021. Forecasting intraspecific changes in distribution of a wide-ranging marine predator under climate change Oecologia 1-14.https://doi.org/10. 1007/s00442-021-05075-7
Niella, Y., H. Flávio, A.F. Smoothey, K. Aarestrup, M.D. Taylor, V.M. Peddemors, and R. Harcourt. 2020a. Refined Shortest Paths (RSP): Incorporation of topography in space use estimation from node-based telemetry data. Methods in Ecology and Evolution 11: 1733-1742. https://doi.org/10.1111/2041-210x.13484.

Niella, Y., A.F. Smoothey, V. Peddemors, and R. Harcourt. 2020 b. Predicting changes in distribution of a large coastal shark in the face of the strengthening East Australian Current. Marine Ecology Progress Series 642: 163-177. https://doi.org/10.3354/ meps13322.

Nolan, S.E.F., D.D. Johnson, R. Hanamseth, I.M. Suthers, and M.D. Taylor. 2021. Reproductive biology of female blue swimmer crabs in the temperate estuaries of south-eastern Australia. Marine and Freshwater Research. https://doi.org/10.1071/ MF21191.

Norse, E.A. 1977. Aspects of the zoogeographic distribution of Callinectes (Brachyura: Portunidae). Bulletin of Marine Science 27: 440-447.

Nurdiani, R., and C. Zeng. 2007. Effects of temperature and salinity on the survival and development of mud crab, Scylla serrata (Forskål), larvae. Aquaculture Research 38: 1529-1538. https:// doi.org/10.1111/j.1365-2109.2007.01810.x.

Oke, P.R., M. Roughan, P. Cetina-Heredia, G.S. Pilo, K.R. Ridgway, T. Rykova, M.R. Archer, R.C. Coleman, C.G. Kerry, and C. Rocha. 2019. Revisiting the circulation of the East Australian Current: Its path, separation, and eddy field. Progress in Oceanography 176: 102139. https://doi.org/10.1016/j.pocean.2019.102139.

Pankhurst, N.W., and P.L. Munday. 2011. Effects of climate change on fish reproduction and early life history stages. Marine and Freshwater Research 62: 1015-1026. https://doi.org/10.1071/ Mf10269.

Payne, N.L., M.D. Taylor, Y.Y. Watanabe, and J.M. Semmens. 2014. From physiology to physics: Are we recognizing the flexibility of biologging tools? Journal of Experimental Biology 217: 317-322. https://doi.org/10.1242/jeb.093922.

Pedersen, E.J., D.L. Miller, G.L. Simpson, and N. Ross. 2019. Hierarchical generalized additive models in ecology: An introduction with mgcv. PeerJ 7: e6876. https://doi.org/10.7717/peerj.6876.

Pittman, S., and C. McAlpine. 2003. Movements of marine fish and decapod crustaceans: Process, theory and application. Advances in Marine Biology 44: 205-294. https://doi.org/10.1016/s00652881(03)44004-2.

R Development Core Team 2019. R: A language and environment for statistical computing. Vienna Austria: R Foundation for Statistical Computing.

Raviv, S., S. Parnes, and A. Sagi. 2008. Coordination of reproduction and molt in decapods. Reproductive Biology of Crustaceans: CRC Press.

Reinfelds, I., T. Cohen, P. Batten, and G. Brierley. 2004. Assessment of downstream trends in channel gradient, total and specific stream power: A GIS approach. Geomorphology 60: 403-416. https:// doi.org/10.1016/j.geomorph.2003.10.003.

Robins, J.B., I.A. Halliday, J. Staunton-Smith, D.G. Mayer, and M.J. Sellin. 2005. Freshwater-flow requirements of estuarine fisheries in tropical Australia: A review of the state of knowledge and application of a suggested approach. Marine and Freshwater Research 56: 343-360. https://doi.org/10.1071/Mf04087.

Rogers, L.A., and A.B. Dougherty. 2019. Effects of climate and demography on reproductive phenology of a harvested marine fish population. Global Change Biology 25: 708-720. https://doi.org/10. $1111 / \mathrm{gcb} .14483$.

Romine, J.G., R.W. Perry, S.V. Johnston, C.W. Fitzer, S.W. Pagliughi, and A.R Blake. 2014. Identifying when tagged fishes have been consumed by piscivorous predators: application of multivariate mixture models to movement parameters of telemetered 
fishes. Animal Biotelemetry, 2, 1-13. https://doi.org/10.1186/ 2050-3385-2-3

Roughan, M., H.S. Macdonald, M.E. Baird, and T.M. Glasby. 2011. Modelling coastal connectivity in a Western Boundary Current: Seasonal and inter-annual variability. Deep Sea Research Part II: Topical Studies in Oceanography 58: 628-644. https://doi.org/ 10.1016/j.dsr2.2010.06.004.

Roy, P.S., R.J. Williams, A.R. Jones, I. Yassini, P.J. Gibbs, B. Coates, R.J. West, P.R. Scanes, J.P. Hudson, and S. Nichol. 2001. Structure and function of south-east Australian estuaries. Estuarine, Coastal and Shelf Science 53: 351-384. https://doi.org/10.1006/ ecss.2001.0796.

Ruello, N. 1975. Geographical distribution, growth and breeding migration of the eastern Australian king prawn Penaeus plebejus Hess. Marine and Freshwater Research 26: 343-354. https://doi. org/10.1071/MF9750343.

Scanes, E., P.R. Scanes, and P.M. Ross. 2020. Climate change rapidly warms and acidifies Australian estuaries. Nature Communications 11: 1-11. https://doi.org/10.1038/s41467-020-15550-z.

Scanes, P., A. Ferguson, and J. Potts. 2017. Estuary Form and Function: Implications for Palaeoecological Studies. In: Weckström,K., Saunders, K. M., Gell, P. A. \& Skilbeck, C. G. (eds.) Applications of Paleoenvironmental Techniques in Estuarine Studies. Dordrecht: Springer Netherlands.

Schaeffer, A., A. Gramoulle, M. Roughan, and A. Mantovanelli. 2017. Characterizing frontal eddies along the East Australian Current from HF radar observations. Journal of Geophysical Research: Oceans 122: 3964-3980. https://doi.org/10.1002/2016JC012171.

Schilling, H.T., J.D. Everett, J.A. Smith, J. Stewart, J.M. Hughes, M. Roughan, C. Kerry, and I.M. Suthers. 2020. Multiple spawning events promote increased larval dispersal of a predatory fish in a western boundary current. Fisheries Oceanography 29: 309-323. https://doi.org/10.1111/fog.12473.

Sequeira, A.M.M., M.R. Heupel, M.-A. Lea, V.M. Eguíluz, C.M. Duarte, M.G. Meekan, M. Thums, H.J. Calich, R.H. Carmichael, D.P. Costa, L.C. Ferreira, J. Fernandéz-Gracia, R. Harcourt, A.-L. Harrison, I. Jonsen, C.R. McMahon, D.W. Sims, R.P. Wilson, and G.C. Hays. 2019. The importance of sample size in marine megafauna tagging studies. Ecological Applications 29: e01947. https://doi.org/10.1002/eap.1947.

Simpson, G.L. 2021. gratia: Graceful 'ggplot'-based graphics and other functions for GAMs fitted using 'mgcv'. R package version 0.6.0 ed.

Slesinger, E., O.P. Jensen, and G. Saba. 2021. Spawning phenology of a rapidly shifting marine fish species throughout its range. ICES Journal of Marine Science 78: 1010-1022. https://doi.org/10. 1093/icesjms/fsaa252.

Smith, E.P. 2020. Ending reliance on statistical significance will improve environmental inference and communication. Estuaries and Coasts 43: 1-6. https://doi.org/10.1007/s12237-019-00679-y.

Spaet, J.L.Y., A. Manica, C.P. Brand, C. Gallen, and P.A. Butcher. 2020a. Environmental conditions are poor predictors of immature white shark Carcharodon carcharias occurrences on coastal beaches of eastern Australia. Marine Ecology Progress Series 653: 167-179. https://doi.org/10.3354/meps13488.

Spaet, J.L.Y., T.A. Patterson, R.W. Bradford, and P.A. Butcher. 2020b. Spatiotemporal distribution patterns of immature Australasian white sharks (Carcharodon carcharias). Scientific Reports 10: 1-13. https://doi.org/10.1038/s41598-020-66876-z.

Stocks, J.R., C.A. Gray, and M.D. Taylor. 2014. Testing the effects of near-shore environmental variables on acoustic detections: Implications on telemetry array design and data interpretation. Marine Technology Society Journal 48: 28-35. https://doi.org/ 10.4031/Mtsj.48.1.8.
Swadling, D.S., N.A. Knott, M.J. Rees, H. Pederson, K.R. Adams, M.D. Taylor, and A.R. Davis. 2020. Seagrass canopies and the performance of acoustic telemetry: Implications for the interpretation of fish movements. Animal Biotelemetry 8: 1-12. https:// doi.org/10.1186/s40317-020-00197-w.

Szuwalski, C.S., K.A. Vert-Pre, A.E. Punt, T.A. Branch, and R. Hilborn. 2015. Examining common assumptions about recruitment: A metaanalysis of recruitment dynamics for worldwide marine fisheries. Fish and Fisheries 16: 633-648. https://doi.org/10.1111/faf.12083.

Taylor, M.D., R.C. Babcock, C.A. Simpfendorfer, and D.A. Crook. 2017a. Where technology meets ecology: Acoustic telemetry in contemporary Australian aquatic research and management. Marine and Freshwater Research 68: 1397-1402. https://doi.org/ 10.1071/Mf17054.

Taylor, M.D., A. Becker, N.A. Moltschaniwskyj, and T.F. Gaston. 2017b. Direct and indirect interactions between lower estuarine mangrove and saltmarsh habitats and a commercially important penaeid shrimp. Estuaries and Coasts 41: 1-12. https://doi.org/ 10.1007/s12237-017-0326-y.

Taylor, M.D., R.C. Chick, K. Lorenzen, A.L. Agnalt, K.M. Leber, H.L. Blankenship, G. Vander Haegen, and N.R. Loneragan. 2017c. Fisheries enhancement and restoration in a changing world. Fisheries Research, 186, 407-412. https://doi.org/10.1016/j.fishres.2016.10. 004

Taylor, M.D., and D.D. Johnson. 2021. Connectivity between a spatial management network and a multi-jurisdictional ocean trawl fishery. Ocean \& Coastal Management 210: 105691. https://doi.org/ 10.1016/j.ocecoaman.2021.105691.

Walsh, C.T., I.V. Reinfelds, R.J. West, C.A. Gray, and D.E. van der Meulen. 2012. Distribution and movement of catadromous fish: Design and implementation of a freshwater-estuarine acoustic telemetry array. American Fisheries Society Symposium 76: 251-264.

Wargo Rub, A.M. and B.P. Sandford. 2020. Evidence of a 'dinner bell' effect from acoustic transmitters in adult Chinook salmon. Marine Ecology Progress Series, 641, 1-11. https://www.int-res. com/abstracts/meps/v641/p1-11/

Webley, J.A., R.M. Connolly, and R.A. Young. 2009. Habitat selectivity of megalopae and juvenile mud crabs (Scylla serrata): Implications for recruitment mechanism. Marine Biology 156: 891-899. https://doi.org/10.1007/s00227-009-1134-0.

West, L.D., K.E. Stark, J.J. Murphy, J.M. Lyle, and F.A. OchwadaDoyle. 2016. Survey of recreational fishing in New South Wales and the ACT, 2013/14. Fisheries Final Report Series No. 149. NSW Department of Primary Industries, Nelson Bay.

Wckham, H. 2016. ggplot2: Elegant Graphics for Data Analysis. New York: Springer-Verlag.

Wickham, H., M. Averick, J. Bryan, W. Chang, L.D.A. Mcgowan, R. François, G. Grolemund, A. Hayes, L. Henry, and J. Hester. 2019. Welcome to the Tidyverse. Journal of Open Source Software, 4, 1686. https:// doi.org/10.21105/joss.01686

Williams, M., and B. Hill. 1982. Factors influencing pot catches and population estimates of the portunid crab Scylla serrata. Marine Biology 71: 187-192. https://doi.org/10.1007/Bf00394628.

Wood, S.N. 2003. Thin plate regression splines. Journal of the Royal Statistical Society: Series B (statistical Methodology) 65: 95-114. https://doi.org/10.1111/1467-9868.00374.

Wood, S.N. 2011. Fast stable restricted maximum likelihood and marginal likelihood estimation of semiparametric generalized linear models. Journal of the Royal Statistical Society: Series B 73: 3-36. https://doi.org/10.1111/j.1467-9868.2010.00749.x.

Wood, S.N. 2017. Generalized additive models: an introduction with $R$, Chapman and Hall/CRC press. 